\title{
Letter
}

\section{Good Cell and Tissue Culfure Practice 2.0 (GCCP 2.0) - Draft for Stakeholder Discussion and Call for Action}

\author{
David Pamies ${ }^{1}$, Marcel Leist 2,3, Sandra Coecke4, Gerard Bowe4, Dave Allen ${ }^{5}$, Gerhard Gstraunthaler6, \\ Anna Bal-Price 4 , Francesca Pistollato ${ }^{4}$, Rob deVries 7,8 , Thomas Hartung 2,9 and Glyn Stacey 10,11,12 \\ ${ }^{1}$ Department of Biomedical Science, University of Lausanne, Lausanne, Vaud, Switzerland; ${ }^{2}$ Center for Alternatives to Animal Testing (CAAT) Europe, \\ University of Konstanz, Konstanz, Germany; ${ }^{3}$ In vitro Toxicology and Biomedicine, Dept inaugurated by the Doerenkamp-Zbinden Foundation, \\ University of Konstanz, Konstanz, Germany; ${ }^{4}$ European Commission Joint Research Centre (JRC), Ispra, Italy; ${ }^{5}$ Integrated Laboratory Systems, LLC., \\ Morrisville, NC, USA; ${ }^{6}$ Medical University Innsbruck, Department of Physiology, Innsbruck, Austria; ${ }^{7}$ Evidence-based Toxicology Collaboration, \\ Johns Hopkins Bloomberg School of Public Health, Baltimore, MD, USA; ${ }^{8}$ SYRCLE, Department for Health Evidence, Radboud Institute for Health \\ Sciences, Radboud UMC, Nijmegen, The Netherlands; ${ }^{9}$ Center for Alternatives to Animal Testing (CAAT), Johns Hopkins University, Bloomberg \\ School of Public Health, Baltimore, MD, USA; ${ }^{10}$ International Stem Cell Banking Initiative, Barley, Herts, UK; ${ }^{11}$ National Stem Cell Resource Centre, \\ Institute of Zoology, Chinese Academy of Sciences, Beijing, China; ${ }^{12}$ Innovation Academy for Stem Cell and Regeneration, Chinese Academy of \\ Sciences, Beijing, China
}

\section{Introduction}

Following the organization of a first symposium on Good Cell Culture Practice (GCCP) for the German Society for Cell Biology (DGZ) in 1996 by Thomas Hartung, teaming up with Gerhard Gstraunthaler, the $3^{\text {rd }}$ World Conference on on Alternatives and Animal Use in the Life Sciences in Bologna, Italy, in 1999 took up this topic. Discussing challenges in the performance of reliable in vitro studies using cells and tissues led to the Bologna declaration toward GCCP (Gstraunthaler and Hartung, 1999).

"The participants ... call on the scientific community to develop guidelines defining minimum standards in cell and tissue culture, to be called Good Cell Culture Practice ... should facilitatetheinterlaboratorycomparabilityofinvitroresults ... encourage journals in the life sciences to adopt these guidelines..."

The European Centre for the Validation of Alternative Methods (ECVAM) of the European Commission then established a taskforce to generate a Good Cell Culture Practice guidance document that would address the key principles required to assure reproducibility and quality of in vitro (cell-based) assays (Hartung et al., 2002). The ECVAM task force of cell biologists drawn from academic research, industry and safety testing backgrounds published the first GCCP principles of best practice in 2005 (Coecke et al., 2005). GCCP addresses issues related to:

- Characterization \& maintenance of essential characteristics

- Quality assurance
- Recording

- Reporting

- Safety

- Education and training

- Ethics

The GCCP documents formed a major basis for a GLP advisory document for in vitro studies published by the OECD (2005).

In 2007, following the increasing use of technologies to culture human embryonic and pluripotent stem cells, the ECVAM Task Force was re-formed to produce a special supplementary GCCP document on considerations for good practice in the culture of human pluripotent stem cells "Human embryonic stem cell (hESC) technology for toxicology and drug development: summary of current status and recommendations for best practice and standardization. The Report and Recommendations of an ECVAM Workshop"1.

More recently, two OECD working groups proposed a revision of GCCP and a series of taskforce workshops were held around the world to consider the needs for new GCCP principles to address the new cellular, molecular and engineering tools, which had come into common use since 2005. This led to an OECD Guidance Document on Good In Vitro Method Practices (GIVIMP) (OECD, 2018). The guidance cross-references and appends the at that time available GCCP documents (Eskes et al., 2017).

Under the leadership of the Johns Hopkins Center for Alternatives to Animal Testing (CAAT), two workshops were held in 2015 in Baltimore, USA, and Konstanz, Germany, as part of the

\footnotetext{
1 https://bit.ly/2ZSEZw9 (accessed 09.07.2020)
}

ALTEX 37(3), 490-492. doi:10.14573/altex.2007091

Correspondence: Thomas Hartung, MD PhD

Johns Hopkins Bloomberg School of Public Health

Department of Environmental Health \& Engineering

Center for Alternatives to Animal Testing (CAAT)

$615 \mathrm{~N}$. Wolfe St, Baltimore, MD 21205, USA

(thartun1@jhu.edu)
This is an Open Access article distributed under the terms of the Creative Commons Attribution 4.0 International license (http://creativecommons.org/licenses/by/4.0/) which permits unrestricted use, distribution and reproduction in any medium, provided the original work is appropriately cited. 
transatlantic think tank for toxicology $-\mathrm{t}^{4}$ (Pamies et al., 2017, 2018). These workshop reports were utilized by a CAAT-initiated expert drafting group to produce a revised version of GCCP called GCCP 2.0, which is available now as supplement ${ }^{2}$ to this article to initiate an open public consultation prior to final publication.

The six original principles of GCCP published in 2005 (Coecke et al., 2005) provided a comprehensive and robust paradigm to help assure the reproducibility of cell and tissue culture-based experimental work, which has been referenced by numerous organizations including the UK's Medical Research Council, the European Society for Animal Cell Technology, and the European Society for In Vitro Toxicology amongst others. These principles are:

1. Establishment and maintenance of a sufficient understanding of the in vitro system and of the relevant factors which could affect it.

2. Assurance of the quality of all materials and methods, and of their use and application, in order to maintain the integrity, validity, and reproducibility of any work conducted.

3. Documentation of the information necessary to track the materials and methods used, to permit the repetition of the work, and to enable the target audience to understand and evaluate the work.

4. Establishment and maintenance of adequate measures to protect individuals and the environment from any potential hazards.

5. Compliance with relevant laws and regulations, and with ethical principles.

6. Provision of relevant and adequate education and training for all personnel, to promote high quality work and safety.

GCCP 2.0 consolidates these principles but also incorporates new key cell culture technologies which have come into more common use since 2005 .

\section{Key developments in the GCCP 2.0 document}

The GCCP 2.0 document reflects on the implications of new technologies and scientific discoveries that have advanced in vitro cell culture systems. In this respect, it has, in particular, considered 3D culture, microphysiological systems, genetically modified cells and pluripotent stem cells. Special considerations of each of these are detailed in each updated chapter for each principle.

Microphysiological systems have rapidly developed in recent years with examples able to model responses in ten or more different tissues in a single integrated bioreactor system (Marx et al., 2016, 2020). The conclusions from the unpublished ECVAM taskforce on human embryonic stem cell culture of $2007^{1}$ have been incorporated and further developed in GCCP 2.0, and new information specific to induced pluripotent stem cells has been added. Specific considerations of good practice in the generation and use of reporter and gene-edited cell lines also has been included. Addressed as a new and important part of principle 2, the document also implements a key and very challenging require- ment for quantified characterization of cells to facilitate the establishment of meaningful acceptance criteria to help assure a better defined in vitro culture state, reduced variation of cultures, and improved accuracy of cell culture-derived data.

Parallel work on Good In Vitro Reporting Standards (GIVReSt) (Hartung et al., 2019; Krebs et al., 2019) also has been incorporated, but this work will continue under the auspices of the CAAT GCCP working group.

\section{The GCCP 2.0 open consultation and review process}

The draft GCCP 2.0 manuscript is hereby published for public comment as supplement ${ }^{2}$ to this article. Over the last few years, a Scientific Advisory Committee (SAC GCCP 2.0) has been formed. We invite all interested stakeholders to join the SAC. Applicants will be able to apply from the day of the publication of this paper and are expected to be bona fide cell culture practitioners. Please send an email to: CAAT@jhu.edu

All members of the SAC will have the opportunity to suggest revisions of the text, starting beginning of September 2020, ending end of November 2020. On acceptance, the new SAC members will receive a commentary template to utilize. Comments will only be considered when accompanied by a specific line number reference in the manuscript and a proposal for a specific change to the text and completed templates. The platform for this process is under development and will be communicated to the SAC volunteers.

All SAC members will be able to vote on the revisions suggested in December 2020. At the beginning of 2021, following a final revision by the steering group, the guidance will be published, and a number of dissemination activities will be started.

It is hoped that this public consultation will assure an open and scientifically intense review of GCCP 2.0 across cell culture experts in various fields of research, in vitro testing, biotechnology development and industry. The GCCP 2.0 steering group has developed a dissemination plan, which will be activated before the public release of GCCP 2.0 and will include consultation with journal editors and life science funding organizations. Furthermore, the new extended SAC will be asked to propose and assist with future dissemination opportunities.

The final publication will hopefully provide a go-to good practice reference for students, those coming to use cell culture for the first time or existing cell culture practitioners wishing to use new cell culture systems. The establishment and implementation of the revised guidance promises to improve the quality of research for an important part of the toolbox in the life sciences.

\section{References}

Coecke, S., Balls, M., Bowe, G. et al. (2005). Guidance on good cell culture practice. A report of the second ECVAM task force on good cell culture practice. Altern Lab Anim 33, 261-287. doi:10.1177/026119290503300313

\footnotetext{
2 doi:10.14573/altex.2007091s
} 
Eskes, C., Boström, A.-C., Bowe, G. et al. (2017). Good cell culture practices \& in vitro toxicology. Toxicol In Vitro 45, 272277. doi:10.1016/j.tiv.2017.04.022

Gstraunthaler, G. and Hartung, T. (1999). Bologna declaration toward good cell culture practice. Altern Lab Anim 27, 206.

Hartung, T., Balls, M., Bardouille, C. et al. (2002). Report of ECVAM task force on good cell culture practice (GCCP). Altern Lab Anim 30, 407-414. doi:10.1177/026119290203000 404

Hartung, T., de Vries, R., Hoffmann, S. et al. (2019). Toward good in vitro reporting standards. ALTEX 36, 3-17. doi:10.14573/ altex.1812191

Krebs, A., Waldmann, T., Wilks, M. F. et al. (2019). Template for the description of cell-based toxicological test methods to allow evaluation and regulatory use of the data. ALTEX 36, 682699. doi:10.14573/altex.1909271

Marx, U., Andersson, T. B., Bahinski, A. et al. (2016). Biology-inspired microphysiological system approaches to solve the prediction dilemma of substance testing using animals. ALTEX 33, 272-321. doi:10.14573/altex.1603161
Marx, U., Akabane, T., Andersson, T. B. et al. (2020). Biology-inspired microphysiological systems to advance medicines for patient benefit and animal welfare. ALTEX 37, 365-394. doi:10.14573/altex.2001241

OECD (2005). Guidance Document on the Validation and International Acceptance of New or Updated Test Methods for Hazard Assessment. OECD Series on Testing and Assessment, No. 34. http://bit.ly/24oFedN

OECD (2018). Guidance Document on Good In Vitro Method Practices (GIVIMP). OECD Series on Testing and Assessment, No. 286. OECD Publishing, Paris. doi:10. 1787/9789264304796-en

Pamies, D., Bal-Price, A., Simeonov, A. et al. (2017). Good cell culture practice for stem cells and stem-cell-derived models. ALTEX 34, 95-132. doi:10.14573/altex.1607121

Pamies, D., Bal-Price, A., Chesné, C. et al. (2018). Advanced good cell culture practice for human primary, stem cellderived and organoid models as well as microphysiological systems. ALTEX 35, 353-378. doi:10.14573/altex.1710081

\title{
Corrigendum
}

\section{Corrigendum to An Advanced In Vitro Model to Assess Glaucoma Onset}

\author{
Sergio C. Saccà 1, Sara Tirendi2,3, Sonia Scarfì 4, Mario Passalacqua², Francesco Oddone ${ }^{5}$, Carlo E. Traverso ${ }^{1,6}$, \\ Stefania Vernazza ${ }^{5 \#}$ and Anna M. Bassi2,3\# \\ ${ }^{1}$ IRCCS, San Martino General Hospital, Ophthalmology Unit, Genoa, Italy; ${ }^{2}$ Department of Experimental Medicine (DIMES), University of Genoa, \\ Genoa, Italy; ${ }^{3}$ Inter-University Center for the Promotion of the 3Rs Principles in Teaching \& Research (Centro 3R), Italy; ${ }^{4}$ Department of Earth, \\ Environmental and Life Sciences (DISTAV), University of Genoa, Genoa, Italy; ${ }^{5}$ IRCCS-Fondazione Bietti, Rome, Italy; ${ }^{6}$ Eye Clinic of Genoa, \\ San Martino General Hospital, Department of Neuroscience, Rehabilitation, Ophthalmology, Genetics, Maternal and Child Health (DiNOGMI), \\ University of Genoa, Genoa, Italy
}

In this manuscript, which appeared in ALTEX 37, 265-274 (doi: 10.14573/altex.1909262), the affiliation of Stefania Vernazza should read:

Stefania Vernazza ${ }^{\text {\# }}$

${ }^{5}$ IRCCS-Fondazione Bietti, Rome, Italy

and the address for correspondence should read:

\footnotetext{
Stefania Vernazza, PhD,

IRCCS, Fondazione Bietti

via Livenza 3, 00198 Rome, Italy

(stefania.vernazza@yahoo.it).
}

doi:10.14573/altex.1909262e 